\title{
Spatial Drought Monitoring in Thar Desert Using Satellite-Based Drought Indices and Geo-Informatics Techniques ${ }^{\dagger}$
}

\author{
Muhammad Bilal 1, Muhammad Usman Liaqat 1,*, Muhammad Jehanzeb Masud Cheema 1,2, \\ Talha Mahmood ${ }^{1}$ and Qasim Khan ${ }^{3}$ \\ 1 Department of Irrigation and Drainage, University of Agriculture, Faisalabad 38000, Pakistan; \\ mohammad.bilal25@gmail.com (M.B.); mjm.cheema@gmail.com (M.J.M.C.); talha2647@gmail.com (T.M.) \\ 2 USPCAS-AFS, University of Agriculture, Faisalabad 38000, Pakistan \\ 3 Department of Civil and Environmental Engineering, United Arab Emirates University, Al Ain 15551, \\ UAE; qasim.raza@uaeu.ac.ae or 201670249@uaeu.ac.ae \\ * Correspondence: usmanliaqat0321@gmail.com; Tel.: +971-503-646-784 \\ + Presented at the 2nd International Electronic Conference on Water Sciences, 16-30 November 2017; Available \\ online: http://sciforum.net/conference/ecws-2.
}

Published: 16 November 2017

\begin{abstract}
Drought is a continuous process in Thar Desert, Pakistan. The extent of this drought needs to be assessed for future land use and adaptation. The effect of previous drought on vegetation cover of the Thar region was studied, through combined use of drought indices and geographic information (GIS) techniques. Five years $(2002,2005,2008,2011$ and 2014) were selected to analyze the drought conditions and land use pattern of the Thar region. The drought indices used in this study included the Normalized Difference Vegetation Index (NDVI) and the Standard Precipitation Index (SPI). Images of past drought were compared with post-drought images of our targeted area and land use maps were developed for spatio-temporal analysis. The results of the study revealed that vegetation in Thar showed an improving trend from 2002 to 2011 and then declined from 2011 to 2014. The rainfall occurred at a below average rate and SPI values for each year were calculated to be negative, indicating below average rainfall. This actual precipitation data was then compared with the data obtained from the Tropical Rainfall Measuring Mission (TRMM) satellite and R2; Pearson correlation coefficients were also calculated. The $\mathrm{R}^{2}$ values for the years 2002 and 2014 were 0.519 and 0.670 respectively. In the same manner, the Pearson correlation coefficient values for the years 2002 and 2014 were 0.721 and 0.867 respectively. The results showed the TRMM satellite's over-estimation in calculating rainfall data. Further, the average temperature for the five years under study was analyzed by graphical representation and it was revealed that the temperature of Thar has increased by almost $1^{\circ} \mathrm{C}$ during the last decade.
\end{abstract}

Keywords: drought indices; MODIS; TRMM; meteorological data

\section{Introduction}

Droughts are a natural phenomenon which can be caused by many factors such as insufficient precipitation, high temperature, high evapo-transpiration, depletion of ground water and exploitation of water resources etc. [1]. Being a normal part of the climate, drought can occur almost anywhere on earth. They usually occur in areas which experience less than normal precipitation over a prolonged duration of time, usually months and years [2].

Like many other parts of the world, most of the area of Pakistan suffers from extreme drought. The presence of drought for a longer period of time is extremely harmful and presents a challenge 
for agriculture and livestock, as well as the lifestyle and health of humans, food security, water management, forestation and various other factors [3]. According to a report issued by the Economic Survey of Pakistan, drought is one of the factors responsible for poor growth performance in the country [4]. The main cause of drought in Pakistan is the lack of rain in the monsoon season.

Remote sensing platforms can provide large amounts of data quickly and inexpensively relative to other means of collection and GIS can bring together vast amounts of information from a wide variety of sources and make the information quickly visible and applicable in emergency situations [5]. The data is mostly available in digital form, i.e., remote sensing images, digital elevation model (DEM), and Global positioning System (GPS) field data; data integration is a common method used for analysis and interpretation. Environmental, urban, precision farming, and agriculture are applications that have benefited from this integration [6].

The impacts of drought were monitored by [6] in Great Southern Plains of the US. The values used in this study are the NDVI values which have been obtained from Terra Moderate Resolution Imaging Spectro-radiometer (MODIS) of the year 2001 and the LST (Land Surface Temperature) values. Another study was carried out by [7] to develop a relationship between meteorological drought indices from all 254 Texas counties and the Vegetation Condition Index (VCI) during 18 growing seasons (March to August, 1982-1999). The results showed that environmental factors are a major hurdle to producing a reliable relationship between the VCI and metrological data and the study must be considered with caution. Agricultural drought monitoring was successful when conducted in Indonesia [8]. Satellite-borne remote sensing data are tested for monitoring drought extent in about 184.486 ha. The results revealed that the vegetation health index fell by more than half from 30.86 in 2000 to 14.66 in 2015 . The severity is mainly linked with the rising land surface temperature from $27^{\circ} \mathrm{C}$ in 2000 to $40^{\circ} \mathrm{C}$ in 2015 as well as the decreasing tendency of NDVI values which causes agricultural fields to become more susceptible to drought.

Similarly, different vegetation and drought indices were employed for drought estimation [913]. However, few studies are available in data-scare regions such as Thar Desert. Therefore, keeping in view the importance of drought assessment, an effort is made to check the spatial distribution of drought in Thar Desert using satellite-based drought indices. The second objective of this study is to analyze the effect of drought on land use change within Thar Desert.

\section{Materials and Methods}

\subsection{Study Area}

Thar Desert is located approximately between Latitudes $24^{\circ} 15^{\prime} \mathrm{N}$ and $25^{\circ} 45^{\prime} \mathrm{N}$ and Longitudes $69^{\circ} 45^{\prime} \mathrm{E}$ and $70^{\circ} 45^{\prime} \mathrm{E}$ in the southern part of Sindh Province, as shown in Figure 1. Most of Thar Desert is situated in the Sindh province and it is one of the biggest deserts in the world. The frequency of droughts has caused much suffering and difficulties. The desert area of Tharparkar district, generally known as Thar, consists of the talukas of Mithi, Chachro and Nagar and parts of the Diplo and Umerkot talukas. 


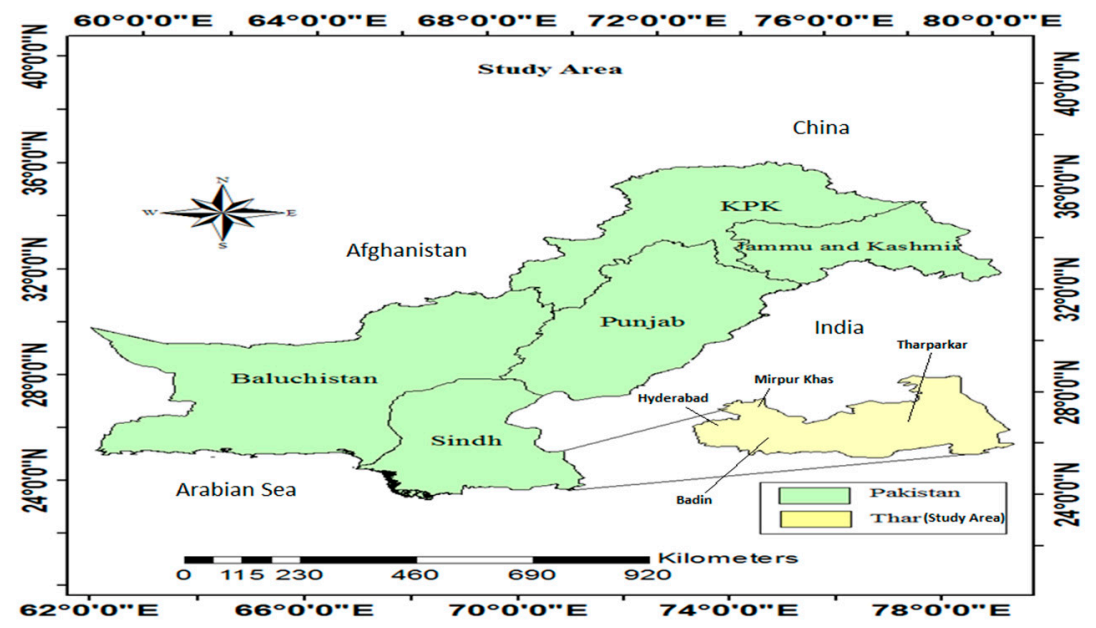

Figure 1. The Administrative Boundary of Thar Desert, Pakistan.

The total area of the desert is 22,000 square kilometers and the population is between 0.7 and 0.8 million. The animal population is estimated at 1.5 to 1.8 million. Except for the south-eastern part of the Nagar taluka, the desert consists of sand dunes between which are flat plains where agriculture can take place.

\subsection{Modis Data}

MODIS 250-m vegetation data was employed to estimate and map the presence of drought. For drought forecasting, we used a time series of 8-day composite clear-sky MODIS product MOD09Q1, tile numbers h24/v05 and h24/v06 from 2013/2014 and 2002/2003, respectively, which were mosaicked together to mask, reproject and subset the area before being converted into the vegetation index.

\subsection{Climatic Data}

The metrological data including Precipitation data and Temperature Data (minimum and maximum) is obtained from Pakistan Metrological Department for the years 2002 and 2014 to monitor the effects of climatic parameters on vegetation change.

\subsection{Drought Indices}

The Normalized Difference Vegetation Index (NDVI) and Standard Precipitation Index (SPI) were used in this study to monitor the spatial variation of drought in Thar Desert. The NDVI is an Index of plant "greenness" or photosynthetic activity, and is one of the most commonly used vegetation indices to analyze the health status of crop [14].

$$
N D V I=(N I R-R E D) /(N I R+R E D)
$$

The SPI is given as the ratio of difference between the normalized seasonal precipitation and its long-term seasonal mean to the standard deviation. It is calculated for different time scale with precipitation as the only input parameter.

$$
S P I=\frac{X_{i j}-X_{i m}}{\sigma}
$$

\section{Results and Discussions}

\subsection{Land Use/Land Cover Classification}

The spatial maps of land use/land cover classification using MODIS for the years 2002, 2005, 2008, 2011 and 2014 are presented in Figure 2 to understand the change detection that occurred in the Thar Region. 

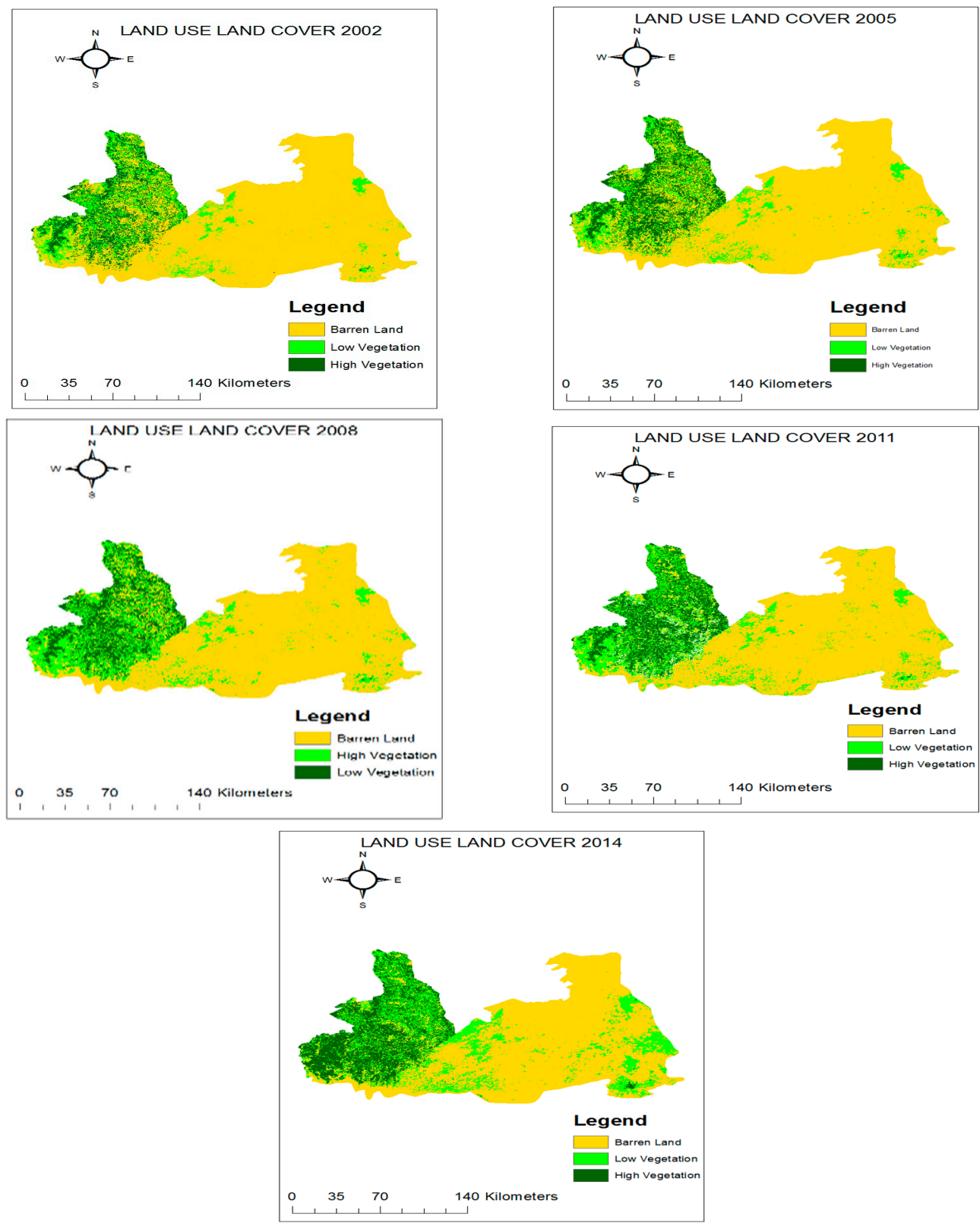

Figure 2. Comparison of Land use/Land cover (LULC) classification based on MODIS from 2002 to 2014.

Figure 2 shows 15 years of land use/land cover classification with 3-year intervals. The Land use/land cover maps indicate that vegetation cover in Thar Desert showed an improving trend from 2002 to 2011 and then declined in the year 2014. This indicated the presence of drought in Thar to date. Table 1 summarizes the classified area.

Table 1. Summary of LULC Change in Thar Region.

\begin{tabular}{cccc}
\hline \multirow{2}{*}{ Year } & \multicolumn{3}{c}{ Area (mha) } \\
\cline { 2 - 4 } & Barren Land & Moderate Vegetation & High Vegetation \\
\hline 2002 & 2.736 & 0.595 & 0.379 \\
2005 & 2.667 & 0.597 & 0.445 \\
2008 & 2.476 & 0.789 & 0.445 \\
2011 & 2.350 & 0.791 & 0.570 \\
2014 & 2.638 & 0.649 & 0.423 \\
\hline
\end{tabular}


As evident from Table 1, most of Thar was barren land. In the year 2002, due to high temperature throughout the year and an extreme shortage of rainfall, the total barren land covered approximately 2.74 mha. A very low level of vegetation, including shrubs, etc., was present on the land measuring $0.595 \mathrm{mha}$. Dense vegetation was present in the western part of Thar on a total land area of $0.379 \mathrm{mha}$. The year 2014 showed an improving trend in vegetation as compared to the year 2002, thereby displaying an increase in vegetative cover. The barren land declined to $2.182 \mathrm{mha}$. The low vegetative cover in 2014 covers a total land area of 0.901 mha. The high vegetative cover, present on the eastern side of Thar, showed an improving trend and now covers a total area of 0.627 mha. This situation indicates that, over the years, the drought area of Thar is showing an improving trend but there is still the presence of drought in the central and western parts of Thar which needs to be properly addressed.

\subsection{Rainfall Pattern of Thar}

The rainfall data of Thar was obtained from the Pakistan Meteorological Department for the years 2002 and 2014. The variation of rainfall in Thar and its adjoining areas is shown in Figure 3.

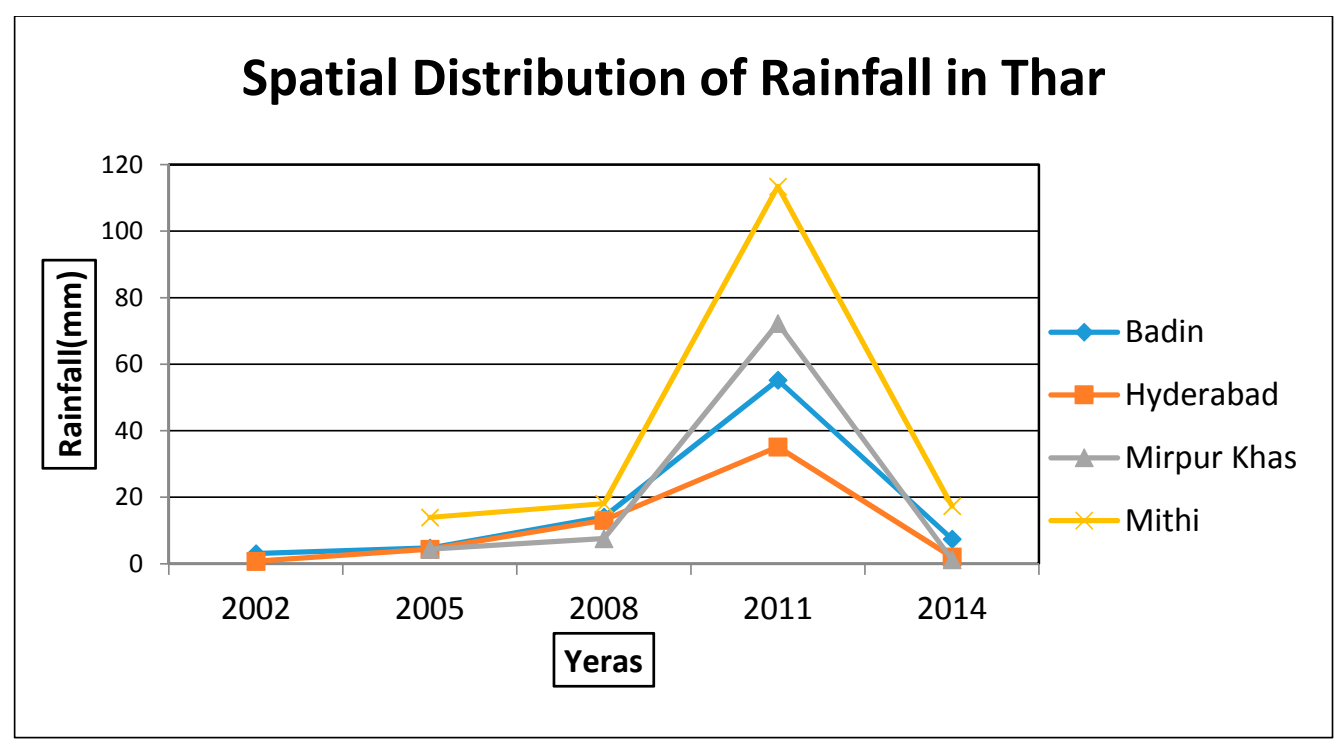

Figure 3. Average Precipitation in adjoining districts of Thar from 2002 to 2014.

The graphical representation of the data shows that the precipitation trend in Thar Desert has improved over the past couple of years and this is the main reason for the decline in barren land and increase in vegetation area, as discussed in the previous section. Comparing both years under observation, the overall precipitation trend seems to be increasing but the average rainfall is still very low compared to the average precipitation necessary for an agricultural area.

\subsection{Rainfall Data Validation at District Level for the Years 2002 and 2014}

A comparison was made at district level between the rainfall statistics of that district and the results extracted from the Tropical Rainfall Measuring Mission (TRMM) Satellite, as presented in Figure $4 \mathrm{a}, \mathrm{b}$. 


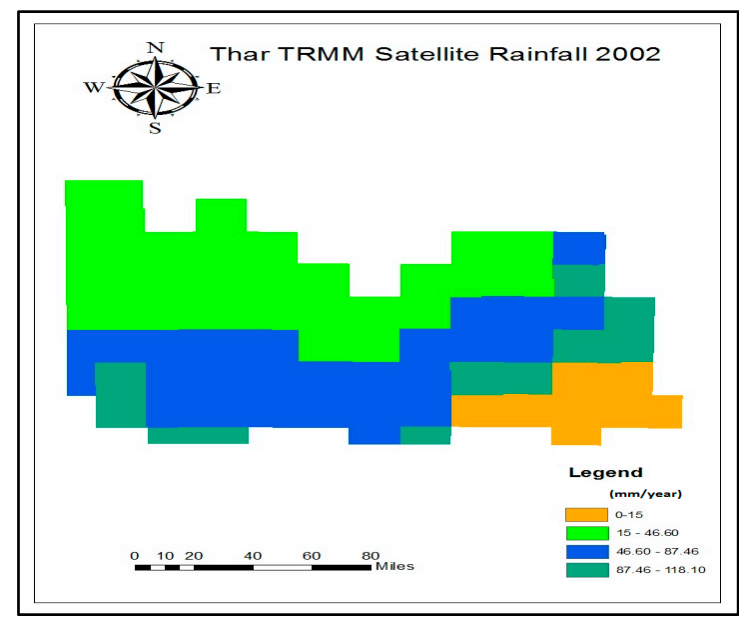

(a)

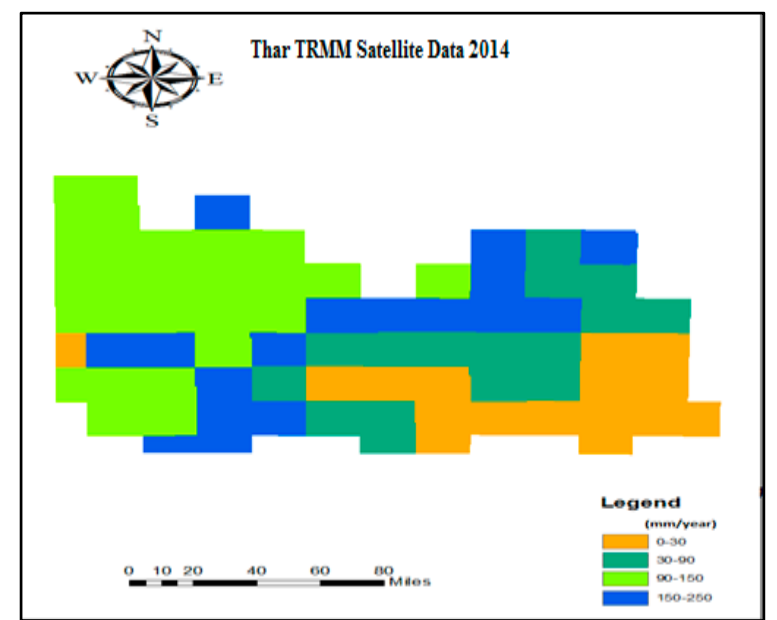

(b)

Figure 4. (a) Relation between Reported and Tropical Rainfall Measuring Mission (TRMM) rainfall (2002); (b) Relation between Reported and TRMM rainfall (2014).

The geospatial analysis of rainfall in the Thar region is shown in Figure 4a,b. It is observed that rainfall intensity decreased over the last 12 years which indicated the occurrence of drought conditions. Moreover, according to (Food and Agriculture Organization) FAO, an area where the average rainfall is below $200 \mathrm{~mm}$ is considered to be a drought-prone area. As evident from the above graphical representation, all areas of Thar received below average rainfall in the year 2002.

Figure 5a,b shows the relationship between the actual observed data received from Punjab Meteorological Department (PMD) and TRMM satellite data. A stronger relationship was observed between TRMM and observed rainfall for the year 2014 as compared to 2002 with $\mathrm{R}^{2}$ and the Pearson coefficient being 0.662 and 0.897 , respectively. The difference between $\mathrm{R}^{2}$ could be due to the scarce pixel and temporal resolution information and non-schematic approaches of departments to collect meteorological data.

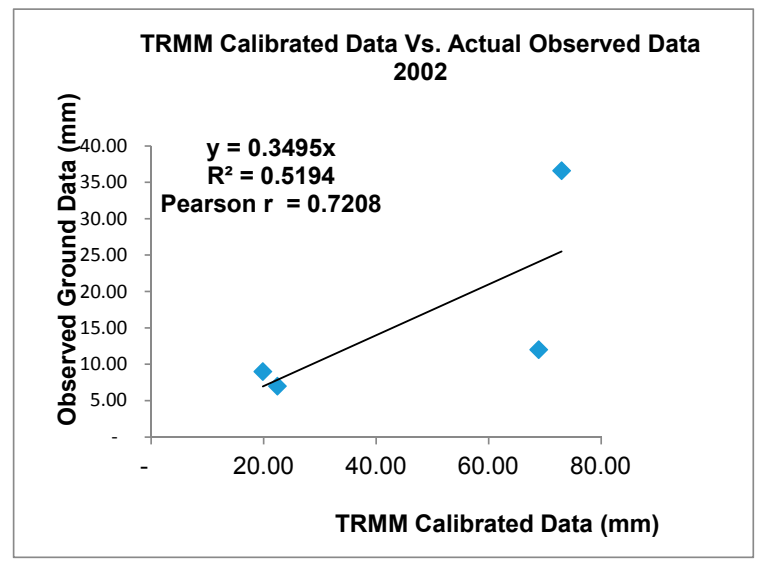

(a)

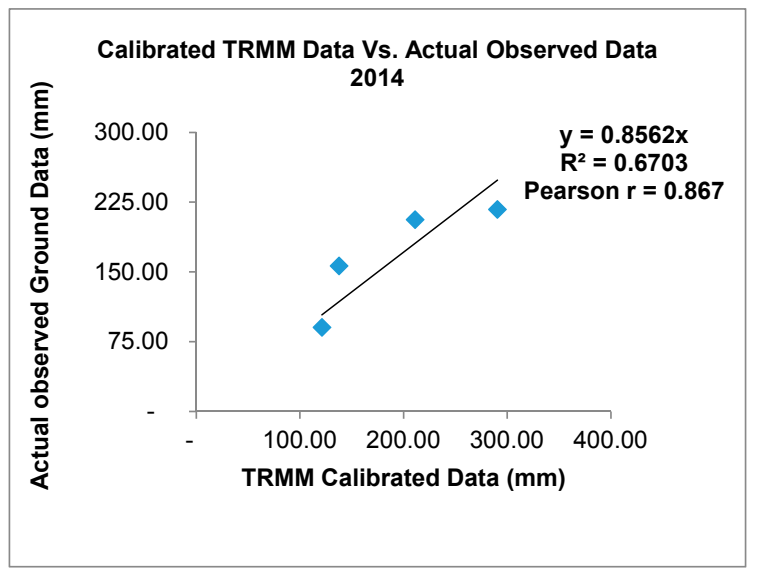

(b)

Figure 5. (a,b) Representation of rainfall detected by the TRMM satellite in Thar and adjoining areas for the years 2002 and 2014.

\subsection{Average Temperature of Thar}

Temperature data was also obtained from the Pakistan Meteorological Department for the years 2002 and 2014. The graphical representation of the data shows that the average temperature increased minutely in the districts of Badin and Mithi. Temperature showed a declining trend in the districts of Hyderabad and Mirpur Khas. The spatial distribution of the temperature from 2002 to 2014 is presented in Figure 6. 


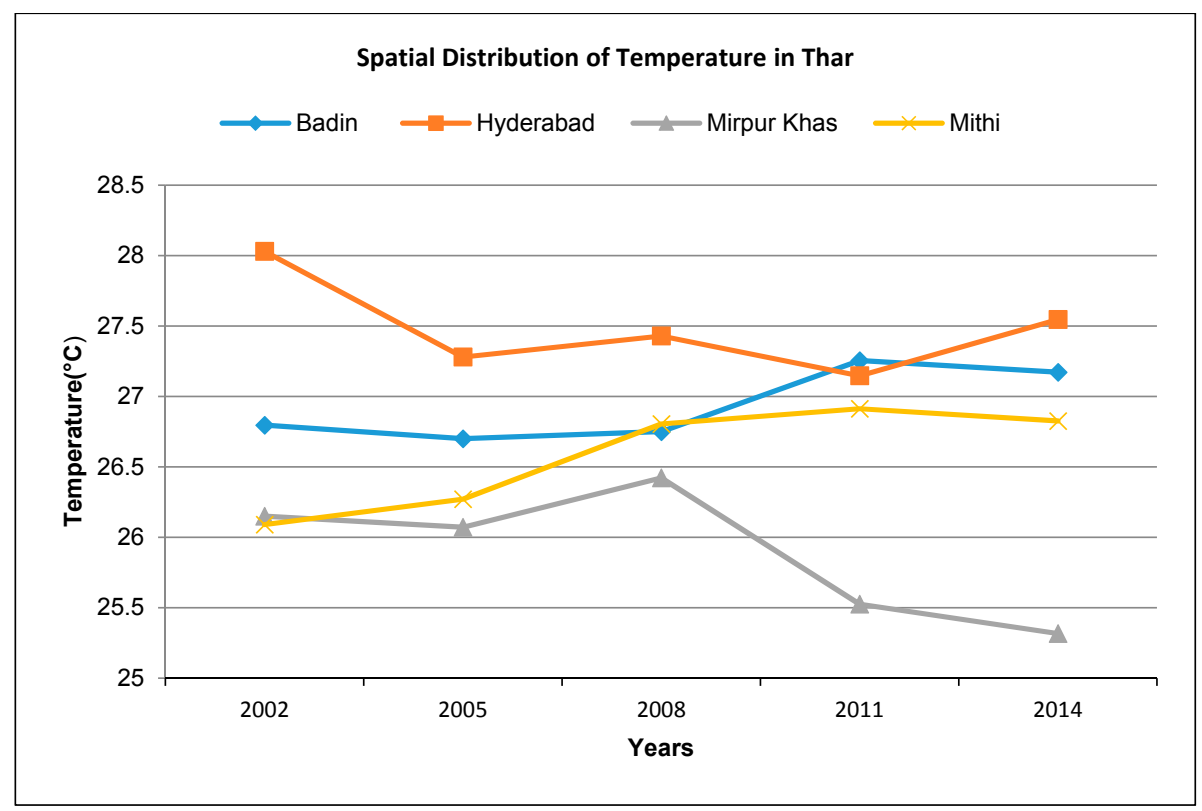

Figure 6. Mean annual temperature in Thar Desert (2002 and 2014).

The temperature data obtained from PMD in Figure 6 shows that there was an increase in the average temperature in Badin, Hyderabad and Mithi districts of Thar while there was a decrease in the temperature observed in the district of Mirpur Khas. The above average temperature, however, still indicates the presence of drought in Thar.

\section{Conclusions}

The spatial distribution of drought over Thar Desert was studied using the NDVI. Land use/land cover maps indicate that vegetation cover in Thar Desert showed an improving trend from 2002 to 2011 and then declined in the year 2014. This indicated the presence of drought in Thar to date. The precipitation data obtained from PMD showed that the precipitation occurred at a below average level. The SPI values were also calculated to be negative which indicated the absence of adequate rainfall in Thar. However, the precipitation trend seemed to have improved when comparing 2014 with 2002. The actual precipitation data was compared with TRMM satellite data. The results revealed that the rainfall data calculated by TRMM was overestimated. Further research will need to be carried out on drought indices by incorporating other factors such as soil condition, temperature, fertility of land and ground water level.

\section{References}

1. Condra, G.E. Drought, Its Effects and Measures of Control in Nebraska; Nebraska Conservation Bulletin 25: Lincoln, NE, USA, 1944; 43p.

2. Wilhite, D.A.; Buchanan, M. Drought as hazard: Understanding the natural and social context. In Drought and Water Crisis: Science, Technology and Management Issues; Wilhite, D.A., Ed.; CRC Press: New York, NY, USA, 2005; pp. 3-29.

3. Hazell, P.; Oram, P.; Chaherli, N. EPTD Discussion Paper No. 8 Environment and Production Technology Division; International Food Policy Research Institute 2033 K Street, N.W.: Washington, DC, USA, 2006.

4. Akhtar, I.U.H. Pakistan Needs a New Crop Forecasting System. 2014. Available online: http://www.scidev.net/en/new-technologies/space-technology/opinions/pakistan-needs-a-new crop forecasting-system.html. Accessed on 13 October 2014

5. Liaqat, M.U.; Cheema, M.J.M.; Huang, W.; Mahmood, T. Inter-comparison of MODIS and LANDSAT multiband vegetation indices used for wheat yield estimation in irrigated indus basin. Comput. Electron. Agric. 2017, 138, 39-47.

6. Wall, L.; Larocque, D.; Leger, P.M. The early explanatory power of NDVI in cropyield modeling. Int. J. Remote Sens. 2008, 29, 2211-2225. 
7. Quiring, S.M.; Ganesh, S. Evaluating the utility of the Vegetation Condition Index (VCI) for monitoring meteorological drought in Texas. Agric. For. Meteorol. 2010, 150, 330-339.

8. Sholihah, R.I.; Bambang, H.; Shiddiq, D.; Panuju, D.R. Identification of agricultural drought extent based on vegetation health indices of Landsat data: Case of Subang and Karawang, Indonesia. Procedia Environ. Sci. 2016, 33, 14-20.

9. Rasheed, S.; Venugopal, K. Land suitability assessment for selected crops in vellore district based on agroecological characterization. J. Indian Soc. Remote Sens. 2009, 37, 615-629.

10. Huang, C.J.; Zhao, S.Y.; Wang, L.C.; Shakeel, A.A.; Chen, M.; Zhou, H.F. Alteration in chlorophyll fluorescence, lipid peroxidation and antioxidant enzymes activities in hybrid ramie (Boehmeria nivea $\mathrm{L}$.) under drought stress. Aust. J. Crop Sci. 2010, 7, 594-599.

11. Yingxin, G.; Bruce, K.W.; Daniel, M.H.; Khem, P.P.; Lei, J. NDVI saturation adjustment: A new approach for improving cropland performance estimates in the Greater Platte River Basin, USA. Ecol. Indic. 2013, 30, 1-6.

12. Xu, D.; Guo, X. Compare NDVI extracted from Landsat 8 imagery with that from Landsat 7 imagery. Am. J. Remote Sens. 2014, 2, 10-14.

13. Sruthi, S.; Aslam, M.A.M. Agricultural Drought Analysis Using the NDVI and Land Surface Temperature Data; a Case Study of Raichur District. In Proceedings of the International Conference on Water Resources, Coastal and Ocean Engineering (Icwrcoe 2015), Mangalore, Karnataka, India, 12-16 March 2015.

14. Cheema, M.J.M.; Bakhsh, A.; Mahmood, T.; Liaqat, M.U. Assessment of Water Allocations Using Remote Sensing and GIS Modeling for Indus Basin, Pakistan; Working Paper No. 036; International Food Policy Research Institute: Washington, DC, USA, 2016.

(C) 2018 by the authors; Licensee MDPI, Basel, Switzerland. This article is an open access article distributed under the terms and conditions of the Creative Commons Attribution (CC BY) license (http://creativecommons.org/licenses/by/4.0/). 